\title{
A EDUCAÇÃO DO CAMPO NO MST COMO FERRAMENTA DE CONSTRUÇÃO DA HEGEMONIA
}

\author{
FIELD EDUCATION IN THE MST AS A HEGEMONY \\ CONSTRUCTION TOOL
}

\section{EDUCACIÓN DE CAMPO EN EL MST COMO HERRAMIENTA DE CONSTRUCCIÓN DE HEGEMONÍA}

\author{
Ramofly Bicalho' \\ Isabella de Mello Leite ${ }^{2}$
}

\begin{abstract}
Resumo: $O$ presente artigo é fruto das pesquisas realizadas no Mestrado em Educação na Universidade Federal Rural do Rio de Janeiro (UFRRJ). Tem como objetivo central realizar um breve apanhado histórico das políticas públicas de educação do campo. Compreender sua notoriedade ao longo dos anos, em consonância com os conceitos Gramsciano. Importa ainda, conhecer como o Movimento dos Trabalhadores Rurais Sem Terra (MST) movimentouse para conquistar tais políticas públicas, a partir dos anos 1990. Utilizamos, predominantemente, a pesquisa bibliográfica e documental. Concluímos que a educação do campo, como práxis libertadora, é utilizada no processo de compreensão das lutas e demandas educacionais defendida pelo MST. Ela dialoga com os gestos, desejos, valores e a luta pela terra, além de contribuir na construção de uma outra hegemonia que oriente sua base militante.
\end{abstract}

Palavras-chave: Políticas Públicas, Educação do Campo, Movimentos Sociais

Abstract: This article is the result of research conducted at the Master of Education at the Federal Rural University of Rio de Janeiro (UFRRJ). Its main objective is to make a brief

\footnotetext{
${ }^{1}$ Doutor em educação pela Universidade Estadual de Campinas (UNICAMP), com Pós-Doutorado em Educação pela Universidade Federal Fluminense (UFF). Atua como Professor Associado II no Departamento de Educação do Campo, Movimentos Sociais e Diversidade do Instituto de Educação da Universidade Federal Rural do Rio de Janeiro (UFRRJ). Integra o quadro docente do Programa de Pós-Graduação em Educação Agrícola (PPGEA) e do Programa de PósGraduação em Educação, Contextos Contemporâneos e Demandas Populares (PPGEduc). ORCID iD http://orcid.org/0000-0003-0571-6481.E-mail: ramofly@gmail.com

2 Mestranda do Programa de Pós-Graduação em Educação, Contextos Contemporâneos e Demandas Populares da Universidade Federal Rural do Rio de Janeiro (UFRRJ); licenciada em Pedagogia pela Universidade do Estado do Rio de Janeiro (UERJ), com Residência Docente no Colégio Pedro II. Atua como Orientadora Pedagógica na Secretaria Municipal de Educação de Nova Iguaçu, RJ, onde Coordena o Setor de Educação do Campo. ORCID iD: http://orcid.org/00000003-4774-9804 E-mail: isabella.melloleite@gmail.com
} 
overview of the public education policies of the field. Understand its notoriety over the years, in line with Gramsciano concepts. It is also important to know how the Landless Rural Workers Movement (MST) moved to conquer such public policies from the 1990s. We use predominantly bibliographic and documentary research. We conclude that field education, as liberating praxis, is used in the process of understanding the struggles and educational demands defended by the MST. It dialogues with gestures, desires, values and the struggle for land, and contributes to the construction of another hegemony that guides its militant base.

Keywords: Public Policies, Rural Education, Social Movements

\begin{abstract}
Resumen: Este artículo es el resultado de una investigación realizada en la Maestría en Educación de la Universidad Federal Rural de Río de Janeiro (UFRRJ). Su objetivo principal es hacer una breve descripción de las políticas de educación pública del campo. Comprender su notoriedad a lo largo de los años, en línea con los conceptos de Gramsciano. También es importante saber cómo el Movimiento de Trabajadores Rurales sin Tierra (MST) se movió para conquistar tales políticas públicas desde la década de 1990. Utilizamos predominantemente la investigación bibliográfica y documental. Concluimos que la educación de campo, como praxis liberadora, se utiliza en el proceso de comprensión de las luchas y demandas educativas defendidas por el MST. Dialoga con gestos, deseos, valores y la lucha por la tierra, y contribuye a la construcción de otra hegemonía que guía su base militante.
\end{abstract}

Palabras clave: Políticas públicas, educación rural, movimientos sociales

\title{
Introdução
}

O presente trabalho é fruto das discussões realizadas no Programa de PósGraduação em Educação, Contextos Contemporâneos e Demandas Populares da Universidade Federal Rural do Rio de Janeiro. A questão central aqui desenvolvida e problematizada, tem como escopo, compreender os sentidos da educação do campo para o Movimento dos Trabalhadores Rurais Sem Terra (MST) na construção da sua hegemonia. As bases teóricas desse trabalho se fundam na tradição marxista, a partir das elaborações do intelectual Antonio Gramsci $^{3}$ na interface com os conceitos e as perspectivas da educação do campo.

Entendemos que a educação, por se constituir, como um complexo social que engloba diversos campos de tensões, pode servir na consolidação da hegemonia da classe dominante. Por outro lado, abre possibilidades para classe trabalhadora se fortalecer intelectual, moral, filosófica e politicamente. Nessa conjuntura, a educação do campo no MST é compreendida num sentido mais amplo de formação política das suas lideranças. A formação humana dos sujeitos, individuais e coletivos, é a base da organicidade do Movimento. Nesta filosofia emancipadora, as escolas do campo, as ocupações de terras, as místicas, marchas e congressos são espaços educativos também inseridos nesta dinâmica de formação política.

\footnotetext{
${ }^{3}$ Gramsci, italiano nascido em Alles, no ano de 1891, se tornou referência no pensamento esquerdista do século XX. A vida de Gramsci foi sempre constituída de lutas. Quando jovem, estudou letras na Universidade de Turim. Suas ideias por política o levaram a fundar o primeiro partido comunista da Itália, pelo qual foi eleito em 1924. Gramsci debatia as estratégias para construção de uma hegemonia da classe trabalhadora, atravessado por influências de outros pensadores, como Marx.
} 


\title{
Educação do campo
}

As políticas públicas de educação do campo nasceram das lutas dos movimentos sociais camponeses, em contraponto à educação rural. Esse modelo de educação, originalmente, esteve vinculado aos trabalhadores do campo, agricultores familiares e sem-terra. Nessa perspectiva, a educação do campo é diferente da educação rural. Ela é construída por diferentes sujeitos, individuais e coletivos, práticas sociais, territórios e culturas que compõem a diversidade do campo. Apresenta-se como uma garantia de ampliação das possibilidades dos camponeses criarem e recriarem suas próprias condições de existência no campo (BICALHO \& OLIVEIRA, 2018). Para Gallo (2017, p. 392), no Dicionário Gramsciano:

\begin{abstract}
A relação entre cidade e campo é, geralmente, caracterizada pelo desprezo, por parte da cidade, em relação a tudo o que tenha a ver com o trabalho camponês no campo, sentimento amplamente retribuído pelos camponeses, mesmo se mesclado a um sentimento de inveja e de inferioridade. No campo imperam a ignorância, o analfabetismo, a alta taxa de fecundidade, frequentemente as mais sinistras aberrações sexuais. A cidade coloca o problema de uma adaptação psicofísica às condições de trabalho, de nutrição, de baixa taxa de natalidade, de habitações que não são "naturais", mas urbanas. Gramsci afirma que as características urbanas adquiridas são passadas por herança ou são absorvidas no desenvolvimento da infância e adolescência. A baixa taxa de natalidade demanda despesas constantes com a formação dos novos "urbanizados" e traz consigo mudanças constantes na composição sociopolítica das cidades, apresentando, portanto, também um problema de hegemonia.
\end{abstract}

Portanto, a educação é uma estratégia importante para transformação da realidade dos sujeitos camponeses, em todas as suas dimensões. Os princípios da educação do campo sinalizam para uma escola do campo organizada coletivamente pelos sujeitos que nela estudam e trabalham. Nesse sentido, essa escola deve ser construída no campo, como garantia dos direitos das crianças, dos jovens e adultos. Ela interfere, diretamente, na produção crítica e emancipadora do conhecimento, pois não está deslocada da realidade dos sujeitos, individuais e coletivos. Nessa conjuntura, estudar, produzir e viver no campo, pode contribuir na desconstrução da lógica de que se estuda para sair do campo (SIADE \& XIMENES-ROCHA, 2018).

A constituição de 1988 deu contribuições importantes, mesmo que indiretamente, na luta pelo direito à educação da população rural. É dever do Estado prover a educação para todos, independentemente de cor, raça, sexo ou localização. No artigo 205 sustenta as reivindicações por direitos sociais: " $A$ educação, direito de todos e dever do Estado e da família, será promovida e incentivada com a colaboração da sociedade, visando ao pleno desenvolvimento da pessoa, seu preparo para o exercício da cidadania e sua qualificação para o trabalho" (BRASIL, 1988).

A Constituição de 1988 abre caminhos para efetivação de novas conquistas, por meio de intensas manifestações da sociedade brasileira, representada dentre tanto atores, pelos movimentos sociais do campo, como por exemplo: o Movimento dos Trabalhadores Rurais Sem Terra (MST). Neste Movimento, desde sua origem em 1984, é possível perceber um conjunto de luta por educação que contemple, de fato, a população camponesa. Uma dessas conquistas iniciais se revela com a Lei $n^{\circ} 9.394$, de 20 de dezembro de 1996, que estabelece a Lei de Diretrizes e Bases da Educação 
Nacional (LDB). Ela institui, em seu artigo 28, os seguintes direcionamentos para as escola do campo:

Art. $28^{\circ}$. Na oferta de educação básica para a população rural, os sistemas de ensino promoverão as adaptações necessárias à sua adequação às peculiaridades da vida rural e de cada região, especialmente: I - conteúdos curriculares e metodologias apropriadas às reais necessidades e interesses dos alunos da zona rural; II organização escolar própria, incluindo adequação do calendário escolar às fases do ciclo agrícola e às condições climáticas; III - adequação à natureza do trabalho na zona rural. (BRASIL/MEC, LDB, 9.394/96, art. 28).

Apesar de ser uma conquista significativa na construção de um plano pedagógico que dialogue com a vida no campo, a LDB de 1996 recebe algumas críticas, por deixar de abordar, de modo mais evidente, questões importantes para prática pedagógica com eficiência. Como evidência Leite (1999, p. 55-56):

1. Quanto à clientela da escola rural: a condição do aluno como trabalhador rural; distâncias entre locais de moradia/trabalho/escola; heterogeneidade de idade e grau de intelectualidade; baixas condições aquisitivas do alunado; acesso precário a informações gerais.

2. Quanto à participação da comunidade no processo escolar: um certo distanciamento dos pais em relação à escola, embora as famílias tenham a escolaridade como valor sócio-moral.

3. Quanto à ação didático-pedagógica: currículo inadequado, geralmente, estipulado por resoluções governamentais, com vistas à realidade urbana; estruturação didático-metodológica deficiente; salas multisseriadas; calendário escolar em dissonância com a sazonalidade da produção; ausência de orientação técnica e acompanhamento pedagógico; ausência de material de apoio escolar tanto para professores quanto para alunos.

Entre os anos de 1996 a 2010 muitas conquistas importantes foram efetivadas, por intermédio das reivindicações do Movimento da Educação do Campo, entre elas: Resolução CNE/CEB n 1/2002 e Resolução CNE/CEB n²/2008, estipulando as Diretrizes Operacionais para Educação Básica das Escolas do Campo e o Decreto $n^{\circ} 7.352$, de 4 de novembro de 2010, que dispõe sobre a Política Nacional de Educação do Campo e sobre o Programa Nacional de Educação na Reforma Agrária (PRONERA). Para Gramsci, de acordo com o Dicionário Gramsciano:

Na realidade, toda geração educa a nova geração, isto é, forma-a; e a educação é uma luta contra os instintos ligados às funções biológicas elementares, uma luta contra a natureza, a fim de dominá-la e criar o homem "atual" à sua época. Nos cadernos a questão da educação é estendida ao tema da hegemonia e do papel fundamental de mediação desenvolvido pelos intelectuais. A questão pedagógicoeducativa aparece desde o caderno 1 como parte do mais vasto discurso sobre a formação e o papel dos intelectuais na história italiana do século XIX. Gramsci distingue os dois modos com os quais uma classe realiza sua supremacia: como domínio sobre os grupos adversários, ou como direção intelectual e moral sobre os grupos afins e aliados; nesse quadro, os intelectuais não existem como classe autônoma e independente, mas como camada que cada classe fundamental elabora como seu instrumento específico (Chiara Meta, 2017, p. 790).

Gramsci disserta sobre educação, em geral, mas poderíamos utilizar seus escritos quando se refere a educação do campo, pois considera que a classe dominante realiza sua supremacia através da educação. Segundo Fernandes, Cerioli e Caldart (2009), a 
educação do campo precisa ser específica e diferenciada, isto é, alternativa. Sobretudo, deve ser educação no sentido amplo de formação humana. Aquela que constrói referências culturais e políticas para intervenção dos sujeitos sociais na realidade, visando uma humanidade mais plena, crítica, consciente e emancipadora.

\section{Perspectiva gramsciana}

Gramsci dedica-se, entre outros, aos conceitos de cultura e hegemonia. Para ele, é na hegemonia que compreendemos o domínio ideológico de uma classe sobre a outra, através da cultura. Nessa conjuntura, a dominação de classe acontece por duas vias indissociáveis: coerção / força e consenso / ideologias. A ideologia é instrumento da luta de classes. A luta pela hegemonia da classe trabalhadora está diretamente relacionada com a construção de uma nova cultura, onde homens e mulheres coletivamente fazem história, num processo dialético.

Nesse sentido, o papel dos intelectuais orgânicos em Gramsci é importantíssimo para compreender que os sujeitos, individuais e coletivos, desenvolvem inúmeras atividades intelectuais. Eles contribuem no enfrentamento ou manutenção das ideologias e concepções de mundo. Cada classe ou frações de classes geram suas camadas de intelectuais que lhe conferem organicidade e homogeneidade. Portanto, os intelectuais orgânicos não formam um grupo à parte e isolado. Estão infiltrados no terreno das lutas de classes. Nesse sentido, compreenderemos o conceito de Hegemonia no Dicionário de Educação do Campo e no Dicionário Gramsciano.

De acordo com o Dicionário de Educação do Campo, o conceito de Hegemonia integra a tradição marxista e foi sistematizado por Antonio Gramsci, em duas direções simultâneas: 1) explicar as formas específicas de produção e organização do convencimento em sociedades capitalistas; 2 ) pensar as condições das lutas de classe subalternas. $O$ conceito apreende a dinâmica dessas lutas de classes sob a dominação burguesa, exemplificando que a produção da conformidade social, por meio da organização e atuação da sociedade civil, está voltada tanto para o convencimento, quanto a persistência / manutenção das formas coercitivas do Estado Burguês.

De acordo com o Dicionário Gramsciano, o conceito de Hegemonia é descrito como "supremacia" (p. 457). Grasmci sinaliza que a supremacia é fundamental para manter a dicotomia da classe dominante: dirigente / consenso e dominante / coersão. Dirigente das classes aliadas e dominante das classes adversárias. Portanto, uma determinada classe, mesmo antes de chegar ao poder, pode ser dirigente e quando se está no poder, dominante. Prevalece uma combinação de força e consenso que se equilibram. Por outro lado, existem situações nas quais o aparelho hegemônico racha e o exercício da hegemonia torna-se sempre mais difícil (hegemonia $\mathrm{x}$ domínio).

Em Gramsci (1986) é possível encontrar leituras mais profundas e acuradas sobre hegemonia. Ela se constitui a partir das análises de determinadas situações concretas e mediações vinculadas à totalidade social, decorrente das possíveis articulações dialéticas entre questões sociais, políticas e econômicas, e não apenas, definições ou estratégias conceituais. Para Gramsci (1986), a hegemonia se torna tangível no momento do consenso e adesão a determinado projeto societário. A hegemonia como 
prática estabelece posicionamentos e comportamentos políticos, que por ora se fazem eivados de concepções, valores, ideologias, ou seja, manifestações próprias do mundo da cultura.

No Dicionário de Educação do Campo, não é possível separar o conceito de hegemonia de uma concepção ampliada do Estado. Nesta concepção ampliada de Estado, a sociedade civil ocupa um importantíssimo espaço no exercício da função hegemônica. Ela é a arena privilegiada das lutas de classes nos chamados "Aparelhos Privados de Hegemonia - APH". Esses APHs são organizações que elaboram e moldam as vontades coletivas, com base nas formas de dominação que se difundem, generalizando modalidades de convencimento adequadas às frações de classes dominantes. Convencimento que passa a ser tarefa permanente e fundamental da burguesia no fortalecimento da sua capacidade de organização e consentimento dos dominados. Nesse sentido, as relações e práticas sociais vigentes são interiorizadas como necessárias e legítimas.

Para Gramsci, as disputas hegemônicas alteram e recompõem as formas de dominação burguesa. Nesse sentido, é extremamente necessário que os trabalhadores construam suas organizações e invistam na formulação intelectual para superar a fragmentação do senso comum. Ao mesmo tempo, se apropriem criticamente da alta cultura, elevando-a e disseminando-a para toda humanidade. Gramsci sinaliza que a direção intelectual dos trabalhadores pode contribuir para superar a divisão da sociedade em classes, valorizando a integração das classes subalternas.

De acordo com o Dicionário Gramsciano (2017), os Aparelhos Privados de Hegemonia - APH, surgem num contexto de formação da opinião pública. Gramsci afirma no caderno 6 que ninguém é desorganizado e sem partido, desde que se compreendam organização e partido de maneira ampla, numa determinada sociedade. Nesta multiplicidade de sociedades particulares, uma ou mais prevalecem, constituindo o aparelho hegemônico de um determinado grupo social sobre o restante da população ou sociedade civil.

De acordo com o Dicionário da Educação do Campo, a implantação dos Aparelhos Privados de Hegemonia - APH, contribui na criação de um novo terreno ideológico. Ele determina uma reforma das consciências e dos métodos de conhecimento filosófico. É possível introduzir uma nova moral, conforme as novas concepções de mundo. Ou seja, determina-se uma completa reforma filosófica. Para Gramsci, um "aparelho" colabora na criação de um novo terreno ideológico. Ele afirma uma nova concepção de mundo. Os aparelhos de hegemonia são mecanismos essenciais na luta hegemônica. Cumprem a função de reproduzir, na "guerra de posição", predominantemente, os interesses da classe dominante.

Nesse sentido, não é por acaso, que a educação emancipadora e a formação política são apontadas, em documentos, congressos e seminários organizados pelo Movimento dos Trabalhadores Rurais Sem Terra, como questões primordiais na consolidação de uma nova sociedade. A leitura de tais documentos e diretrizes indica que o processo de formação da militância, baseado na organicidade dos sujeitos, individuais e coletivos, é estratégica e historicamente faz parte da trajetória e bandeiras de lutas do MST. Nessa conjuntura, de apropriação dos fundamentos teóricos de 
Gramsci, apresentaremos o MST como Aparelho Privado de Hegemonia, numa intensa relação entre educar, sentir e pensar, em diálogo, com as classes populares camponesas.

\section{O movimento dos trabalhadores rurais sem terra}

De acordo com o próprio site do MST, o Movimento dos Trabalhadores Rurais Sem Terra é um movimento socioterritorial que agrupa e reúne diversos camponeses pobres, além de diferentes pessoas adeptas às lutas sociais pela terra, Reforma Agrária e mudanças na agricultura familiar brasileira. Tem como diferencial na consolidação do movimento, a participação intensa de crianças, jovens e adultos, homens e mulheres de todas as regiões do país. A luta do MST vai além da simples conquista da terra. Ela está diretamente ligada a vários setores de atuação: cultura, educação, produção, saúde, formação de base, gênero, entre outros. Esses aspectos credenciam o Movimento como importante sujeito coletivo de ressocialização e articulador do desenvolvimento territorial no Brasil. Suas ações contribuem para o desenvolvimento do país e empoderamento dos camponeses e camponesas.

A educação é essencialmente uma das prioridades do MST desde os primeiros acampamentos no início da década de 1980. Para Kolling, Vargas e Caldart (2012, p. 500), "a história da educação no MST tem relação direta com o percurso do movimento como um todo". A luta pelo direito à educação e pelo acesso às escolas públicas, entra na agenda do MST logo nas primeiras ocupações. Nessas ocasiões, percebem-se a necessidade do cuidado pedagógico e a produção do conhecimento crítico e emancipador para crianças e jovens dos acampamentos. Nessa conjuntura de preocupação com a organização das lutas, o Movimento cria o Setor de Educação. (KOLLING; VARGAS; CALDART, 2012, p. 501), nos apresenta a seguinte trajetória:

\footnotetext{
No início, na década de 1980, a visão da necessidade e do direito ia até a educação para crianças e adolescentes. Aos poucos, na década de 1990, destaca-se também a alfabetização e da educação de jovens e adultos, que, em experiências pontuais, também já acontecia desde os primeiros acampamentos. Depois, veio a preocupação e o trabalho com a educação infantil e, mais recentemente, com a educação universitária. Na educação de nível médio, o trabalho começou com cursos alternativos para a formação dos professores das escolas conquistadas, e logo se estendeu a formação de técnicos para as experiências de cooperação dos assentamentos. No final dos anos 1990 e no início dos anos 2000, começaram as lutas especificas pelo ensino médio nas áreas de Reforma Agrária ou, mais amplamente, pela conquista de escolas de educação básica, incluindo todas as suas etapas.
}

A organização dos coletivos de educação local, estadual, regional e nacional tem a tarefa de contribuir na mobilização, reflexão e fortalecimento dos princípios organizativos do MST, em especial, as questões de cunho social na sua amplitude. Através das lutas foi possível recolocar a questão da educação do campo na agenda do Ministério da Educação (MEC), das secretarias, conselhos municipais e estaduais de educação. Percebemos, na sua origem, que a luta dos Sem Terra pela garantia de escolas do campo enaltecia os debates acerca dos direitos sociais. Por outro lado, logo perceberam que apenas garantir escola não era suficiente. Necessitam sentir-se parte dela e ver representada sua própria pedagogia. De acordo com Vendramini (2007) as escolas tradicionais não tinham lugar para os sujeitos do campo, pois sua pedagogia, 
na grande maioria das vezes, desconhece ou desrespeita as diversas realidades e especificidades do campo.

Para o Movimento, é necessário construir escolas do campo que garantam o direito ao conhecimento crítico e emancipador, a ciência e tecnologia, que amplie as oportunidades de desenvolvimento humano das pessoas e comunidades. Ao mesmo tempo, reafirme os povos do campo como sujeitos, individuais e coletivos, de seu próprio destino, reconhecendo o campo como território privilegiado de valores e culturas específicas. Nesse sentido, é estratégico que as políticas públicas garantam escolas públicas de qualidade, educando a partir dos diferentes sujeitos do campo e seus contextos (BICALHO \& OLIVEIRA, 2018).

\section{O MST e a luta pela educação do campo}

O MST tem como objetivo, de acordo com seus documentos e diretrizes, a transformação da realidade atual. O desafio da escola, em diálogo com esses objetivos, educa para essa transformação. A proposta de educação do Movimento acompanha uma nova conjuntura de luta, privilegiando a perspectiva de classe na luta pela reforma agrária popular e agroecológica. A década de 1990, embora tenha prevalecido a coerção sobre os movimentos sociais, colaborou com o fortalecimento do MST, em função da sua expressiva combatividade na luta de classes. A educação do campo, em diálogo com a reforma agrária popular e agroecológica, amplia sua contribuição nos debates acerca da luta de classes. No documento Princípios Filosóficos da Educação no MST (1997), encontramos cinco elementos que orientam sua prática pedagógica no campo:

1. Educação para a transformação social. A partir deste princípio filosófico, apontam-se algumas características essencias da proposta de educação do MST, tais como: a) Educação de classe; b) Educação massiva; c) Educação organicamente vinculada ao Movimento Social; d) Educação aberta para o mundo; e) Educação para a ação; f) Educação aberta para o novo.

2. Educação para o trabalho e a cooperação. Este princípio filosófico parte da defesa da relação que a educação e a escola devem ter com a luta pela Reforma Agrária e os desafios para a implementação de novas relações de produção no campo e na cidade.

3. Educação voltada para as várias dimensões da pessoa humana. Neste princípio são apontadas dimensões importantes como a formação política-ideológica; a formação organizativa; a formação técnico-profissional; a formação do caráter ou moral; a formação cultural e estética; a formação afetiva e a formação religiosa. Este princípio se orienta na formação omnilateral do ser humano, a partir das formulações de Karl Marx.

4. Educação com/para valores humanistas e socialistas. Este princípio tem seu compromisso focado na superação dos valores da sociedade atual e a construção de novos valores, mesmo na atualidade, que colocam no centro dos processos de transformação a pessoa humana e sua liberdade, novas relações sociais que visem a produção e a apropriação coletiva dos bens materiais e espirituais da humanidade.

5. Educação como um processo permanente de formação e transformação humana. Este princípio evoca para a crença no potencial transformador da pessoa humana, 
e que a educação tem papel fundamental desde que seja um processo intencionalmente planejado e provocado.

Quanto aos princípios pedagógicos encontramos treze, descritos na seguinte ordem: 1. Relação entre prática e teoria; 2 . Combinação metodológica entre processos de ensino e de capacitação; 3 . A realidade como base da produção do conhecimento; 4. Conteúdos formativos socialmente úteis; 5 . Educação para o trabalho e pelo trabalho; 6. Vínculo orgânico entre processos educativos e processos políticos; 7 . Vínculo orgânico entre processos educativos e processos econômicos; 8 . Vínculo orgânico entre educação e cultura; 9 . Gestão democrática; 10. Autoorganização dos/das estudantes; 11. Criação de coletivos pedagógicos e formação permanente dos educadores/educadoras; 12 . Atitudes e habilidades de pesquisa; 13. Combinação entre processos pedagógicos coletivos e individuais (MST, 1997).

A proposta de educação compreendida pelo MST está relacionada à transformação da sociedade e a construção do socialismo, numa intensa articulação com as lutas defendidas pelo Movimento. A interface entre a luta pela terra e a luta pela educação do campo é configurada pela exigência de organicidade desenvolvida coletivamente no MST. O MST, enquanto movimento de massa, absorveu e se apropriou do trabalho educativo. Caso contrário, deixaria toda a responsabilidade de condução do processo formativo, sob a responsabilidade do Estado, com seus conservadorismos, diretrizes, planejamentos e perspectivas.

\section{Movimento dos trabalhadores rurais sem terra como aparelho hegemônico}

A partir do I Encontro Nacional de Educadores e Educadoras da Reforma Agrária (I ENERA), em 1997, o MST encampa um conjunto de lutas pela educação, calcada no campo das políticas públicas. O Movimento assume para si a bandeira da educação do campo como estratégica na luta pelo acesso à educação, a fim de fortalecer a correlação de forças na luta pela hegemonia dentro da sociedade. Importante na atual conjuntura, mostrar que a produção do consenso - direção intelectual e moral - surge no momento em que o MST realiza articulações internacionais com frações da mesma classe (via campesina) e frações de classes distintas (UNICEF, UNESCO).

Estudar é um direito e a escola do campo deve ter uma educação que contribua para que os trabalhadores rurais se apropriem de sua história, tornando-se sujeitos com capacidade de transformar a realidade social donde vivem. Trata-se de uma educação que combine o estudo com o trabalho, cultura e organização coletiva, [...] uma educação que recupere valores socialistas. (Caderno de Formação - MST n. 18 , 1999, p. 14)

Este novo cenário representa um marco diferencial na relação entre a proposta de educação do MST e as bandeiras da educação do campo, como luta por políticas públicas orientadas através dos Organismos Multilaterais, (Organização das Nações Unidas para a Educação, a Ciência e a Cultura (UNESCO), Fundo das Nações Unidas para a Infância (UNICEF)) e, posteriormente, assumida pelo Estado capitalista, institucionalizada nos documentos da educação do campo. Compreenderemos o contexto que emerge os debates acerca da educação do campo, como luta por política 
pública (hegemonia), analisando o significado da ampliação da educação no MST e as parcerias estabelecidas entre as frações de classes distintas, representadas principalmente pelos movimentos sociais camponeses e os Organismos Multilaterais, como UNICEF e UNESCO.

\section{A luta por política pública de educação do campo}

Em princípio, historicamente a educação no MST, sempre foi ponto de pauta, em função de questões pragmáticas, como por exemplo, a necessidade de formação política de suas lideranças e militantes, além da escolarização das crianças, jovens e adultos acampados e assentados da reforma agrária. O Movimento logo percebeu que os processos educativos ocupavam espaços estratégicos de formação crítica e emancipadora direcionada a partir de seus interesses.

No contexto das políticas neoliberais da década de 1990, iniciam-se as discussões entorno do que seria a educação do campo. Segundo Dalmagro (2010, p. 180) foi a partir de 1998 que o debate sobre a educação do campo tem entrada no MST, "este debate se estende até hoje e deixará marcas na perspectiva de educação do Movimento". Para a autora, o vínculo do MST com a Via Campesina, retoma gradativamente os conceitos de campo e campesinato, "apontando que há uma cultura, um modo de vida camponês que deve ser respeitado e em certa medida retomado como forma de assegurar a sobrevivência da população campesina" (DALMAGRO, 2010, p. 180).

Consideramos que a trajetória da educação do campo teve seu marco histórico em 1997, a partir da realização do I ENERA (Encontro Nacional de Educadores e Educadoras da Reforma Agrária). Este encontro, promovido pelo MST, juntamente com a Universidade de Brasilia (UNB), UNICEF, UNESCO e Confederação Nacional dos Bispos do Brasil (CNBB), reuniu educadores e educadoras da reforma agrária de todo Brasil. (KOLLING; NÉRY; MOLINA, 1999, p. 13). O I ENERA foi realizado logo após o MST receber o prêmio "Educação e Participação", concedido pelo Fundo das Nações Unidas para a Infância (UNICEF), em dezembro de 1995, por seu trabalho na área da educação. Este reconhecimento público repercutiu, positivamente, na organicidade do Movimento, por conta do trabalho cotidiano desenvolvido há anos nas escolas de assentamentos e acampamentos. Igualmente, abriu portas, caminhos e possibilidades de atuação junto à sociedade, universidades, secretarias municipais e estaduais de educação.

Esta premiação 4 representou o reconhecimento do esforço realizado pelo setor de educação do MST, em garantir o acesso e a permanência dos sujeitos, individuais e coletivos, em atividades que privilegiou os debates acerca da educação popular. Colaborou ainda, com a projeção do MST e sua participação nos fóruns de educação, exigindo uma maior qualificação dos membros do setor de educação, no terreno das políticas públicas (BICALHO \& OLIVEIRA, 2018). Nunca antes, as lideranças do Movimento tinham sido convidadas, com tanta frequência, para participarem de

\footnotetext{
${ }^{4}$ O prêmio concedido ao MST em 1995 se trata da primeira edição do Prêmio Itaú-Unicef. O projeto enviado pelo MST por intermédio da Associação Nacional de Cooperação Agrícola (ANCA), "Por uma Escola Pública de Qualidade nas Áreas de Assentamento" recebe o segundo lugar nas premiações.
} 
encontros, seminários e congressos na área de educação. Para Caldart (2007), o I ENERA foi um encontro do MST com apoio dos Organismos Multilaterais. No entanto, a preparação do encontro, a definição do caráter e dos conteúdos trabalhados não contou com a participação destes organismos.

Para Caldart (2007), esses organismos representaram, simbolicamente, a legitimação do MST perante a sociedade. A autora afirma ainda que dois fatores importantíssimos possibilitaram a realização do I ENERA: 1) O prêmio da UNICEF recebido pelo MST, reconhecendo o trabalho desenvolvido com a educação popular nos acampamentos e assentamentos da reforma agrária; 2) Os encaminhamentos do III Congresso Nacional do MST, realizado em 1995, com o lema: "Reforma Agrária: uma Luta de Todos". A unidade que se estabelece a partir do I ENERA entre as frações de classes distintas, tem como ponto comum, a luta por políticas públicas de educação do campo.

No final da década de 1990 e início de 2000, com a redução da população do campo, além da política de nucleação das escolas do campo, o Movimento para fortalecer a luta por terra e educação, estabeleu inúmeras parcerias com outros movimentos sociais camponeses, Estado e Organismos Multilaterais. Nessa conjuntura, era muito mais unir alguns parceiros do que produzir uma proposta política, teórica, revolucionária e emancipadora. Considerando os posicionamentos de classes e as divergências estruturais entre movimentos sociais e organismos internacionais, a unidade entre as distintas frações de classes, acontece por meio da luta pelo direito à educação. É fato que nesse contexto histórico, O MST recua em algumas de suas propostas teóricas com a intenção de fortalecer o diálogo com a diversidade de sujeitos, individuais e coletivos. O Movimento, ao invés de avançar num campo mais ofensivo e revolucionário, privilegia o campo da constituição hegemônica mais reformista.

No primeiro volume da coleção Por uma Educação Básica do Campo, os autores fazem referências ao I ENERA - Encontro Nacional de Educadores e Educadoras da Reforma Agrária. Apontam para as parcerias e desafios levantados durante a realização deste Encontro, apresentando o Manifesto dos Educadores e Educadoras da Reforma Agrária. Munarim (2008) considerou este Manifesto, a "certidão de nascimento" do que viria a ser o Movimento Nacional de Educação do Campo. Segundo o (MST, 1999):

\footnotetext{
O "Manifesto das Educadoras e dos Educadores da Reforma Agrária ao Povo Brasileiro" resultante do I ENERA elucida as intenções e fundamenta a base para a I Conferência que resulta na formulação "Educação Básica do Campo". Destacamos aqui a defesa, expressa no Manifesto, em sentido mais amplo, da "escola pública, gratuita e de qualidade para todos, desde a educação infantil até a Universidade", afirmando a necessidade de construir uma "identidade própria das escolas do meio rural" em vistas a novas formas de desenvolvimento do campo, "baseadas na justiça social, na cooperação agrícola, no respeito ao meio ambiente e na valorização da cultura camponesa".
}

Segundo Caldart (2012, p. 260) O argumento para mudar o termo Educação Básica do Campo para Educação do Campo aparece nos debates de 2002, realizados no contexto da aprovação do parecer do Conselho Nacional de Educação (CNE) n ${ }^{\circ}$ 36/2001, relativo às Diretrizes Operacionais para a Educação Básica nas Escolas do Campo (BRASIL, 2002). Esses debates consolidam a participação dos movimentos sociais e sindicais camponeses envolvidos nessa luta, justamente num contexto em que o MST 
se torna um dos maiores adversários do governo FHC. O Movimento era, no período em questão, a fração da classe trabalhadora com maior ênfase no enfrentamento ao Estado brasileiro. Segundo (DALMAGRO, 2010, p. 115):

\footnotetext{
O auge da luta do Movimento foi alcançado entre 1995 e 1998, quando cresceu significativamente o número de ocupações de terras[...]. Nesse período o MST ganhou grande visibilidade nacional tanto pelo massacre de Eldorado dos Carajás, em 1996, como da Marcha Popular pelo Brasil, reunindo cerca de cem mil pessoas em Brasília, no ano de 1997.
}

Se por um lado, o MST representa uma fração da classe trabalhadora bem ativa e forte na luta contra o Estado brasileiro, por outro, há o reconhecimento, por parte dos organismos internacionais, do trabalho realizado com a educação popular e as escolas do campo nas áreas de acampamentos e assentamentos da reforma agrária. Esse reconhecimento é visível por meio do prêmio Itaú-Unicef (1995), além da parceria estabelecida para realização do I ENERA (1997).

\section{Considerações finais}

A efetivação dos marcos normativos referente as políticas públicas de educação do campo, se dá a partir da promulgação das Diretrizes Operacionais para a Educação Básica nas Escolas do Campo, Resolução CNE/CBE n¹ de 03 de abril de 2002. Esta teve como base para sua elaboração, o Parecer $n^{\circ} 36$, de 04 de dezembro de 2001. A Resolução $\mathrm{CNE} / \mathrm{CBE} \mathrm{n}^{\circ} 1$ de 03 de abril de 2002 será reformulada pela Resolução CNE/CEB No 2, de 28 de abril de 2008 e pelo Decreto $n^{\circ} 7.352$, de 4 de novembro de 2010. Nesse sentido, tais políticas públicas de educação do campo são regulamentadas e ampliadas.

Nas legislações apresentadas é evidente a estreita relação entre os interesses do Estado e do capital. Na educação do campo, essa relação também se faz presente. Atribuir ao Estado a função de educador, significa abrir mão de uma educação voltada aos interesses da classe trabalhadora. Ou seja, inversão de funções, onde os movimentos sociais acabam cumprindo com o papel do Estado, segundo suas perspectivas. Identificamos, na maioria dos documentos acerca da educação do campo, orientações no conjunto das políticas focais e fragmentárias, próprias do Estado em sua fase neoliberal. Tais políticas possuem como função básica as recomendações dos organismos internacionais: educação como segurança e alívio da pobreza. As políticas de educação do campo se configuram como táticas e estratégias do Capital para inclusão dos trabalhadores na organização produtiva, garantindo a sobrevivência do sistema capitalista.

Para D'Agostini (2012, p. 464), embora a educação do campo trabalhe na perspectiva da emancipação humana, ao ser desenvolvida na sociedade capitalista e incorporar as contradições gerais entre trabalho e capital, tais contradições expressamse na cisão entre teoria e prática presente no trabalho pedagógico e na materialização das políticas públicas, em sua grande maioria, próximas às orientações dos organismos multilaterais. Nestes termos, a educação do campo está para atender aos objetivos do capital e do Estado, em detrimento às demandas da classe trabalhadora. Se considerarmos do ponto de vista, apenas, o acesso à educação, houve importantes 
avanços para classe trabalhadora no que toca a luta por educação do campo. Ela cumpre com a demanda de qualificação dos trabalhadores e trabalhadoras camponesas.

A educação no Movimento é marcada pelo enfrentamento das lutas de classes distintas. É expressão da ofensiva do capital sobre o trabalho, principalmente, a partir da década de 1990 na construção das políticas públicas de educação do campo. Embora o MST se posicione enquanto fração da classe trabalhadora, em luta contra o capital, no contexto da luta de classe, tende ao enfraquecimento de sua proposta de educação. É possível perceber o reposicionamento da educação de classe para educação nos marcos da luta pelo direito, na lógica do Estado burguês. Este cenário permitiu apontarmos as contradições na trajetória da educação no MST, a partir da luta de classes entre os representantes do capital, com destaque para o Estado e os Organismos Multilaterais - UNICEF e UNESCO e os movimentos sociais camponeses, em especial, o Movimento dos Trabalhadores Rurais Sem Terra.

\section{Referências}

BICALHO, Ramofly; OLIVEIRA, Lia Maria Teixeira. Políticas públicas em Educação do campo: interfaces entre movimentos sociais e atores político-institucionais. RTPS - Rev. Trabalho, Política e Sociedade, Vol. III, nº 04, p. 267-290, jan.-jun./2018 - ISSN 25262319.

BRASIL. Constituição da República Federativa do Brasil. Brasília, DF, Senado, 1998.

BRASIL. Lei de Diretrizes e Bases da Educação Nacional. Lei n 9394, de 20 de dezembro de 1996. Estabelece as diretrizes e bases da educação nacional. Brasília, 1996.

BRASIL. Ministério da Educação. Secretaria de Educação Continuada. Alfabetização e Diversidade. Resolução CNE/CEB n. 1, de 3 de abril de 2002. Institui as diretrizes operacionais para a educação básica nas escolas do campo. Diário Oficial da União, Brasília, DF, 9 de abril de 2002. Seção 1, p. 32.

BRASIL. Resolução CNE/CEB no 01, de 3 de abril de 2002 - Institui Diretrizes Operacionais para a Educação Básica nas Escolas do Campo. Brasília, 2002. Cad. Cedes, Campinas, vol. 27, n. 72, p. 121-135, maio/ago. 2007.

\section{CALDART, R. S.; PEREIRA, I. B.; ALENTEJANO, P.; FRIGOTTO, G. Dicionário da Educação} do Campo. São Paulo: Expressão Popular, 2012.

D'AGOSTINI, A. A educação do campo na educação brasileira: contradições e perspectivas. Educação, Santa Maria, RS, v. 37, n. 3, p. 453-467, dez. 2012.

DALMAGRO, S. L. A escola no contexto das lutas do MST. 2010. 314 f. Tese (Doutorado em Educação) - Universidade Federal de Santa Catarina, Florianópolis, 2010.

FERNANDES, Bernardo M. CERIOLI, Paulo R. CALDART, Roseli S. Primeira Conferência Nacional "Por uma educação básica do campo": texto Preparatório In: ARROYO, Miguel Gonzalez. CALDART, Roseli Salete. MOLINA, Mônica Castagna (organizadores). Por Uma Educação do Campo. $4^{a}$ edição. Petrópolis, RJ: Vozes, 2009. 
KOLLING, E.; VARGAS, M.; CALDART, R. MST e educação. In: CALDART, R. et al. (org.). Dicionário da educação do campo. Rio de Janeiro: Escola Politécnica de Saúde Joaquim Venâncio; São Paulo: Expressão Popular, 2012. p. 502-509.

KOLLING, E. J.; NERY, I.; MOLINA, M. C. Por uma educação básica do campo. Brasília: Fundação Universidade de Brasília, 1999. v. 1.

LEITE, Sérgio Celani. Escola rural: urbanização e políticas educacionais. São Paulo: Cortez, 1999.

LIGUORI, Guido; VOZA, Pasquale (Orgs.). Dicionário gramsciano (1926-1937). - $1^{\text {a }}$. ed. - São Paulo: Boitempo, 2017. 831p.

MOVIMENTO DOS TRABALHADORES RURAIS SEM-TERRA (MST). Caderno de formação $\mathrm{n} .18$ - $3^{\mathrm{a}}$ edição, março de 1999

MOVIMENTO DOS TRABALHADORES RURAIS SEM-TERRA (MST). Disponível em: $<$ www.mst.org.br>

MUNARIM, A. Trajetória do movimento nacional de educação do campo no Brasil. In: MEURER, A. C. (Org.) Dossiê: Educação no Campo. Revista do Centro de Educação. Santa Maria, UFSM, 2008. Vol. 33, $n^{\circ} 1$.

SIADE, Aline Rafaela de Vasconcelos \& XIMENES-ROCHA, Solange Helena. Escola do campo e precarização do trabalho docente. RTPS - Rev. Trabalho, Política e Sociedade, Vol. III, nº 04, p. 107-124, jan.-jun./2018 - ISSN 2526-2319

VENDRAMINI C. R. Educação e trabalho: reflexões em torno dos movimentos sociais do campo - Cad. Cedes, Campinas, vol. 27, n. 72, p. 121-135, maio/ago. 2007.

$\begin{array}{ll}\text { Submetido em: } & \text { 14-11-2019 } \\ \text { Aceito em: } & \text { 02-12-2019 }\end{array}$

